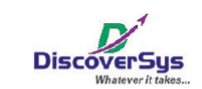

Published by DiscoverSys

\section{Predictor of muscle dysmorphia among members of fitness centers in Denpasar City, Bali, Indonesia}

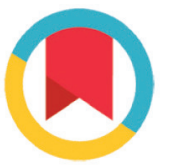

CrossMark

\author{
Vennesa Vitari Maureen Susanto, ${ }^{1 *}$ Dewa Nyoman Wirawan, ${ }^{2}$ I Putu Adiartha Griadhi ${ }^{3}$
}

${ }^{1}$ Public Health Postgraduate Program, Faculty of Medicine, Udayana University ${ }^{2}$ Department of Public Health and Preventive Medicine, Faculty of Medicine, Udayana University ${ }^{3}$ Department of Physiology, Faculty of Medicine, Udayana University
*Correspondence to: Vennesa V.M. Susanto; Public Health Postgraduate Program, Faculty of Medicine, Udayana University; vssusanto22@gmail.com

\section{INTRODUCTION}

In 2016, more than one billion people were estimated to have mental and addictive disorders. ${ }^{1}$ It was also reported that mental and addictive disorders cause 7\% disability-adjusted life years (DALY) and $19 \%$ years lived with disability (YLD). ${ }^{1}$ Overall, two-thirds of DALY are caused by depression, anxiety, drug and alcohol abuse. ${ }^{1}$ World Health Organization (WHO) reported that in 2017 around 264 million people worldwide suffered from anxiety disorder with the highest proportion was in the South-East Asia Region, around 60 million cases or $23 \%$ of the total population. ${ }^{2}$ Anxiety disorders are the top six contributors to non-fatal health loss in the world and are also included in the top ten causes of YLD in all WHO countries. ${ }^{2}$ Generalized anxiety disorder (GAD), obsessive-compulsive disorder (OCD), social anxiety disorder, panic disorder, analysis and multiple linear regression for the multivariate analysis. Results: The prevalence of muscle dysmorphia among fitness center members was $43.6 \%(95 \% \mathrm{Cl}=33.99: 53.20)$ in the total sample based on MDDI cut-off score. Bivariate analysis shows that six variables including body fat percentage, total physical activity, thin/low body fat internalizations, muscular/athletic internalizations, peer pressure, media pressure associated with muscle dysmorphia. In the multivariate analysis, only four variables were significantly associated with muscle dysmorphia, namely: muscular/athletic internalization $(\beta=0.369,95 \% \mathrm{Cl}=0.296: 0776$, $p<0.001)$, media pressure $(\beta=0.277,95 \% \mathrm{Cl}=0.167: 0.595$, $p<0.001)$, body fat percentage $(\beta=-0.262,95 \% \mathrm{Cl}=-0.301:-0.067$, $\mathrm{p}=0.002)$ and body dissatisfaction $(\beta=-0.224,95 \% \mathrm{Cl}=-0.245$ :$0.050, p=0.003$ )

Conclusion: The prevalence of muscle dysmorphia in Denpasar City is relatively high. Muscular/athletic internalization, media exposure, body fat percentage and body satisfaction are associated with increase chance of having muscle dysmorphia.

Keywords: muscle dysmorphia, body dysmorphic disorder, fitness center, body composition

Cite this Article: Susanto, V.V.M., Wirawan, D.N., Griadhi, I.P.A.2020. Predictor of muscle dysmorphia among members of fitness centers in Denpasar City, Bali, Indonesia. Public Health and Preventive Medicine Archive 8(1): 4-10. D01:10.15562/phpma.v8i1.234

post-traumatic stress disorder (PTSD) and phobias are a group of mental disorders that fall into anxiety disorders. ${ }^{2}$

The mental disorders included in OCD are general OCD, body dysmorphic disorder (including muscle dysmorphia), hoarding disorder, trichotillomania (hair-pulling disorder), excoriation (skin-picking) disorder, substance/ medication-induced obsessive-compulsive and related disorder, obsessive-compulsive and related disorder due to another medical condition, and other specified obsessive-compulsive and related disorder and unspecified obsessive-compulsive and related disorder (e.g. body-focused repetitive behavior disorder, obsessional jealousy). ${ }^{3}$

Muscle dysmorphia, also known as bigorexia, is one of the most common forms of body dysmorphic disorder (BDD) and identified as an obsessive- 
compulsive disorder (OCD). ${ }^{3}$ Muscle dysmorphia is a condition where the individual is preoccupied with the idea that his or her body build is too small or insufficiently muscular. ${ }^{3}$ Individuals with muscle dysmorphia usually feel dissatisfied with their body shape, especially body size and muscle mass. They can do extreme things in order to get desired body shape and muscle mass, for example by using dangerous methods or supplements such as human growth hormone, diuretics (water pills), anabolic steroids and ephedrine, whilst some continue to exercise even if they were injured and they are likely to experience a more severe injury such as a broken bone. ${ }^{4}$ People with muscle dysmorphia also have a high risk of suffering from major depression with a living value of $50-60 \%,{ }^{5}$ experience more severe psychopathology and suicidal ideation. ${ }^{6}$ Based on data from the International OCD Foundation, approximately $80 \%$ of individuals with BDD are reported to have suicidal ideation, while $50 \%$ of those with muscle dysmorphia have attempted suicide.

The prevalence of muscle dysmorphia in various countries is reported to vary widely between $1-53.6 \%$, with the proportion in Spain ranged from $1-11 \%,{ }^{8}$ the United States $9.8-23 \%,{ }^{6,9}$ Hungary $15.1 \%,{ }^{4}$ Australia $17 \%,{ }^{10}$ Italy $3.4-25 \%,{ }^{11,12}$ India $44.3 \%{ }^{13}$ Colombia $52 \%{ }^{14}$, Africa $53.6 \%{ }^{15}$ and Turkey $58.3 \% .^{16}$

Studies on muscle dysmorphia have been widely published in western countries but remain limited in Asia, including Indonesia. There was one study conducted in Semarang, Indonesia, which was a cross sectional study of 42 men in a sports club. The study was measuring the energy intake and macro nutrients. ${ }^{17}$ Another study that looked at the association between perfectionism and muscle dysmorphia which was conducted in Surabaya and Bangil, Indonesia involving 100 men in six fitness centers. ${ }^{18}$ The prevalence of muscle dysmorphia and its risk factors yet to be established in Indonesian setting. This study aims to determine the prevalence of muscle dysmorphia and its associated factors among members of fitness centers in Denpasar.

\section{METHODS}

This was a cross-sectional study conducted at fitness centres in Denpasar City, Bali. A fitness centre was eligible to be included in the study if it has supporting equipment for body building and weightlifting activities, has more than 30 members and is not exclusive to one gender only. Twentythree fitness centers met the criteria, from which five centers were selected by simple random sampling.

The minimum required samples for this study was 102 , which was calculated with a significance level of $95 \%$, effect size $15 \%$, the prevalence of body builders/weightlifter (BB/WL) who experienced muscle dysmorphia $58.3 \%{ }^{16}$ the prevalence of non-BB/WL who experienced muscle dysmorphia $5.9 \%{ }^{19}$ Number of samples selected from each center was determined proportionately to the size of members listed in the previous month. Finally, samples were selected consecutively according to the arrival at the fitness centers during data collection, a total of 196 fitness centers members were approached and the final number of samples involved in the analysis was 117.

Data collection was carried out in August 2019 in the five selected fitness centers by five enumerators through face to face interviews and individual physical measurements. Data collected were including socio-demographic characteristics, sports activities, health behaviors, self-internalization, family pressure, peer pressure, media pressure, social comparison, body dissatisfaction and presence of muscle dysmorphia. Physical measurements included measurements of body weight, height and body fat percentage. Body weight was measured with Kris EB9-4A Series digital scales, height with GEA microtoise and body fat percentage with a digital HBF-306 body fat monitor.

Data on self-internalization, family, peer and media pressures were measured with the 4 th edition Sociocultural Attitudes Towards Appearance Scale (SATAQ). The questionnaire consisted of 21 questions using 5 Likert scales $(1=$ never/strongly disagree, $2=$ rarely/disagree, $3=$ sometimes/disagree, $4=$ often/agree, $5=$ very often/strongly agree) with a minimum score of 1 and a maximum of 105. Data on social comparison was measured using The Physical Appearance Comparison Scale (PACS). The PACS questionnaire consisted of 5 questions, using a 5 Likert rating ( $1=$ never/strongly disagree, $2=$ rarely/ disagree, $3=$ sometimes/disagree, $4=0$ often/agree, $5=$ very often/strongly agree) with a minimum score of 1 and a maximum of 25. Data on respondent's dissatisfaction with their bodies was measured using the Body Esteem Scale for Adolescents and Adults (BESAA). The BESAA questionnaire consisted of 21 questions, using a 5 Likert rating ( $1=$ never/strongly disagree, $2=$ rarely/disagree, $3=$ sometimes/disagree, $4=$ often/agree, $5=$ very often/strongly agree) with a minimum score of 1 and a maximum of 105. Data on muscle dysmorphia was measured using The Muscle Dysmorphic Disorder Inventory (MDDI). The MDDI questionnaire consisted of 13 questions, using a 5 Likert rating ( $1=$ never/strongly disagree, $2=$ rarely/disagree, $3=$ sometimes/disagree, $4=\mathrm{often} /$ agree, $5=$ very often/strongly agree) with a minimum score of 1 and a maximum of 65 . The cut-off point for muscle dysmorphia is 39 , with higher score 
reflecting more muscle dysmorphia symptoms. ${ }^{20}$

Statistical analysis was conducted using STATA 12.1 including descriptive, bivariate, and multivariate analysis. Association with $\mathrm{p} \leq 0.05$ were flagged as statistically significant. Correlation between variables was determined by Spearman's Correlation Test and normality of data distribution with Kolmogorov Smirnov Test. Multivariate analysis was performed with multiple linear regression. Independent variables will be included in the regression model if it has $\mathrm{p}<0.25$ in the correlation test. This study has been approved by

Table 1. Prevalence of muscle dysmorphia and socio-demographic characteristics of respondents

\begin{tabular}{|c|c|c|}
\hline Socio-demographic characteristics & $\mathbf{n}$ & $\%$ \\
\hline \multicolumn{3}{|l|}{ Muscle dysmorphia } \\
\hline Score $<39$ & 66 & 56.4 \\
\hline Score $\geq 39$ & 51 & 43.6 \\
\hline \multicolumn{3}{|l|}{ Gender } \\
\hline Male & 81 & 69.2 \\
\hline Female & 36 & 30.8 \\
\hline \multicolumn{3}{|l|}{ Age (years) } \\
\hline $18-24$ & 29 & 24.8 \\
\hline $25-34$ & 46 & 39.3 \\
\hline $35-44$ & 32 & 27.4 \\
\hline $45-54$ & 8 & 6.8 \\
\hline$\geq 55$ & 2 & 1.7 \\
\hline \multicolumn{3}{|l|}{ Marriage status } \\
\hline Not married & 59 & 50.4 \\
\hline Married & 58 & 49.6 \\
\hline \multicolumn{3}{|l|}{ Last education } \\
\hline High school & 41 & 35.0 \\
\hline Diploma & 10 & 8.5 \\
\hline Undergraduate & 66 & 56.4 \\
\hline \multicolumn{3}{|l|}{ Occupation } \\
\hline Private employee & 53 & 45.3 \\
\hline Entrepreneur & 30 & 25.6 \\
\hline Student & 13 & 11.1 \\
\hline Other & 21 & 17.9 \\
\hline \multicolumn{3}{|l|}{ Ethnicity } \\
\hline Bali & 74 & 63.2 \\
\hline Java & 24 & 20.5 \\
\hline Other & 19 & 16.3 \\
\hline \multicolumn{3}{|l|}{ Nutritional status } \\
\hline Under & 2 & 1.7 \\
\hline Normal & 56 & 47.9 \\
\hline Over & 59 & 50.4 \\
\hline \multicolumn{3}{|l|}{ Fat percentage } \\
\hline Low & 2 & 1.7 \\
\hline Normal & 30 & 25.6 \\
\hline Slightly high & 35 & 29.9 \\
\hline High & 50 & 42.7 \\
\hline Total & 117 & 100.0 \\
\hline
\end{tabular}

the Ethics Committee of the Faculty of Medicine, Udayana University/Sanglah General Hospital on July 17, 2019.

\section{RESULTS}

Of the 196 fitness center members approached to involve in the study, 68 (34.7\%) members refused to be interviewed, most of them were women $42(61.8 \%)$. As many as 128 people interviewed, however, 11 (5.6\%) people were excluded in data analysis due to incomplete data in questionnaire. Hence, the final number of participants included in the analysis of this study was 117 fitness center members.

Table 1 presents the prevalence and sociodemographic characteristics of the respondents. The prevalence of muscle dysmorphia (MDDI score 39 or above) was $43.6 \%(95 \% \mathrm{CI}=33.99: 53.20)$. The majority of the participants were male (69.2\%), Balinese $(63.2 \%)$, with a mean age of 31.43 years (SD \pm 9.4$)$. Half of them were single (50.4\%) completed diploma/undergraduate (56.4\%), worked as private employees (45.3\%), and had high nutritional status (50.4\%) with mean body mass index (BMI) of $25.46(\mathrm{SD} \pm 3.74)$ and had a high body fat percentage $(42.7 \%)$.

Table 2 presents median and IQR of independent variables. Median for age was 30 year (IQR:15), body fat percentages was $23.3 \%$ (IQR:11), adjusted FFMI 19.8 (IQR:3.3), BMI $24.9 \mathrm{~kg} / \mathrm{m}^{2}$ (IQR:4.3). Median for physical activity per week was 6.0 hour (IQR:4.5). The highest median score for SATAQ was muscular/athletic internalization with score 19.0 (IQR:4.0), median score for PACS was 15.0 (IQR:8,0), the highest median score for BESAA was appearance satisfaction 23.0 (IQR:4.0), and drive for size for MDDI 14.0 (IQR:6.0).

Table 3 presents the correlation between MDDI score and numeric variables, namely biological risk factors, sports participation, socio-cultural, and psychological. Based on the Spearman test on the twelve predictors included in the analysis, biological variables that showed a significant relationship with MDDI scores was body fat percentage $(r=-0.292, p=0.001)$. Variables that were not significantly related to MDDI scores were BMI $(\mathrm{r}=-0.025, \mathrm{p}=0.786)$ and adjusted FFMI $(\mathrm{r}=0.166$, $\mathrm{p}=0.074$ ). Sports participation that indicated a significant relationship with MDDI scores was physical activity per week ( $\mathrm{r}=0.301, \mathrm{p}=0.001)$. Socio-cultural factors that indicated a significant relationship with muscle dysmorphia were thin/ low body fat internalization $(r=-0.206, p=0.026)$, muscular/athletic internalization $\quad(r=0.480$, $\mathrm{p}<0.001)$, peer pressure $(\mathrm{r}=0.188, \mathrm{p}=0.043)$ and media pressure $(\mathrm{r}=0.251, \mathrm{p}=0.006)$, while ethnicity 
$(\mathrm{r}=0.085, \mathrm{p}=0.085)$ and family pressure $(\mathrm{r}=0.159$, $\mathrm{p}=0.086$ ) did not significantly correlate with the MDDI score. As for psychological factors, there were no variables significantly associated with the occurrence of muscle dysmorphia, where the social comparison had a value of $\mathrm{r}=0.144, \mathrm{p}=0.121$ and

Table 2. Median and IQR of independent variables

\begin{tabular}{lcccc}
\hline Variable & Median & IQR & Min & Max \\
\hline Age (year) & 30.0 & 15,0 & 18,0 & 59,0 \\
Nutritional Status & & & & \\
$\quad$ Body fat $(\%)$ & 23.3 & 11.0 & 6.1 & 44.7 \\
$\quad$ Adjusted FFMI $\left(\mathrm{kg} / \mathrm{m}^{2}\right)$ & 19.8 & 3.3 & 14.2 & 26.2 \\
$\quad$ BMI $\left(\mathrm{kg} / \mathrm{m}^{2}\right)$ & 24.9 & 4.3 & 15.5 & 42.4 \\
Sport Participation (h) & & & & \\
$\quad$ Total physical activity per week & 6.0 & 4.5 & 0.5 & 21.5 \\
SATAQ (score) & 53.0 & 9.0 & 36.0 & 87.0 \\
$\quad$ Thin/low body fat internalization & 15.0 & 5.0 & 8.0 & 17 \\
$\quad$ Muscular/athletic internalization & 19.0 & 4.0 & 8.0 & 25.0 \\
Family pressure & 8.0 & 4.0 & 4.0 & 19.0 \\
Peer pressure & 8.0 & 5.0 & 4.0 & 20.0 \\
$\quad$ Media pressure & 10.0 & 6.0 & 4.0 & 20.0 \\
PACS (score) & 15.0 & 8.0 & 6.0 & 25.0 \\
BESAA (score) & 66.0 & 45.0 & 45.0 & 90.0 \\
$\quad$ Appearance satisfaction & 23.0 & 4.0 & 11.0 & 33.0 \\
Weight satisfaction & 19.0 & 4.0 & 10.0 & 28.0 \\
$\quad$ Attribution & 24.0 & 5.0 & 14.0 & 29.0 \\
MDDI (score) & 37.0 & 8.0 & 26.0 & 48.0 \\
Drive for size & 14.0 & 6.0 & 7.0 & 21.0 \\
Appearance intolerance & 11.0 & 3.0 & 6.0 & 16.0 \\
Functional impairment & 12.0 & 4.0 & 4.0 & 18.0 \\
\hline
\end{tabular}

Table 3. Correlations of MDDI with biological risk factors, sports participation, socio-cultural and psychological factors.

\begin{tabular}{lcc}
\hline Variable & $\mathbf{r}$ & $\mathbf{p}$ \\
\hline Biological factors & & \\
$\quad$ Age & -0.044 & 0.637 \\
BMI & -0.025 & 0.786 \\
$\quad$ Fat percentage & -0.292 & 0.001 \\
$\quad$ Adjusted FFMI & 0.166 & 0.074 \\
Sport participation & & \\
$\quad$ Physical activity per week & 0.301 & 0.001 \\
Social-cultural & & \\
$\quad$ Thin/low body fat internalization & -0.206 & 0.026 \\
$\quad$ Muscular/athletic internalization & 0.480 & $<0.001$ \\
$\quad$ Family pressure & 0.159 & 0.086 \\
$\quad$ Peer pressure & 0.188 & 0.043 \\
$\quad$ Media pressure & 0.251 & 0.006 \\
Psychological factors & & \\
Social comparison & 0.144 & 0.121 \\
$\quad$ Body dissatisfaction & -0.108 & 0.248 \\
\hline
\end{tabular}

body dissatisfaction of $\mathrm{r}=-0.108, \mathrm{p}=0.248$.

Table 4 presents the results of multivariate analysis using multiple linear regression with the backwards method. The final model in the backwards method excluded five variables from the initial model since it did not show a significant relationship with MDDI scores. Those variables were excluded sequentially from the model starting with the variable with the largest p-value. It showed that muscular/athletic internalization variable gave the most significant predictor on MDDI scores as shown by the highest value of standardized coefficient $(\beta)$, followed by media pressure, physical activity per week, body fat percentages and body dissatisfaction.

Muscular/athletic internalization showed a significant positive relationship with muscle dysmorphia $\quad(\mathrm{B}=0.536 ; \quad 95 \% \mathrm{CI}=-0.002: 0.430$; $\mathrm{p}<0.001$ ), meaning if muscular/athletic internalization score has increased by one unit, the MDDI score will increase by 0.536 . Media pressure also showed similar results $(B=0.381$; 95\%CI $=0.167-0.595 ; \quad \mathrm{p}=0.001)$, where score of media pressure increased by one unit, than score MDDI will increase by 0.381 . While the percentage of body fat $(\mathrm{B}=-0.184 ; 95 \% \mathrm{CI}=-0.301$ :$0.067 ; \mathrm{p}=0.002)$ and body dissatisfaction $(\mathrm{B}=-$ $0.148 ; 95 \% \mathrm{CI}=-0.245:-0.050 ; \mathrm{p}=0.003)$ showed a significant negative relationship, meaning if body fat percentage and BESAA score has increased by one unit than score MDDI will decreased by 0.184 and 0.148 , respectively. The physical activity per week ( $B=0.214, \beta=0.153, p=0.052)$, however, showed a borderline in significant association with muscle dysmorphia $(\mathrm{p}=0.052)$, meaning that the higher total physical activity may also play a role in the development of symptoms of muscle dysmorphia. The adjusted R-square value obtained were 0.374 , or the independent variables entered in the model provided a $37.4 \%$ influence to the dependent variable (see Table 4).

\section{DISCUSSION}

The primary objective of this study was to determine the prevalence and predictor of muscle dysmorphia among fitness center member. Among 117 fitness center members participated in the study, 51 members or $43.6 \%$ (95\%CI=34.61:52.58) met the criteria of muscle dysmorphia based on MDDI cut-off value. The prevalence in this study is higher than the other studies which also used the MDDI questionnaire with non-bodybuilder samples, namely in Turin $(5.9 \%),{ }^{19}$ the United States $(7.1 \%)^{21}$ and Norway (35.0\%). ${ }^{22}$ Differences of the prevalence in those studies with finding in our study are possibly because of differences in the 
Table 4. Adjusted regression coefficient of the independent variables

\begin{tabular}{|c|c|c|c|c|c|c|}
\hline \multirow{2}{*}{ Variable } & \multirow{2}{*}{ B } & \multirow{2}{*}{$\beta$} & \multirow{2}{*}{$\mathbf{t}$} & \multicolumn{2}{|c|}{$\mathbf{C l}$} & \multirow{2}{*}{$\mathbf{p}$} \\
\hline & & & & Lower & Upper & \\
\hline Constant & 36.349 & - & 8.410 & 27.784 & 44.914 & $<0.001$ \\
\hline Muscular/athletic internalization & 0.536 & 0.369 & 4.429 & 0.296 & 0.776 & $<0.001$ \\
\hline Media pressure & 0.381 & 0.277 & 3.526 & 0.167 & 0.595 & 0.001 \\
\hline Fat percentage & -0.184 & -0.262 & -3.102 & -0.301 & -0.067 & 0.002 \\
\hline Body dissatisfaction (BESAA) & -0.148 & -0.224 & -2.985 & -0.246 & -0.050 & 0.003 \\
\hline Physical activity per week & 0.214 & 0.153 & 1.967 & -0.002 & 0.430 & 0.052 \\
\hline $\mathbf{R}^{2}$ & & & & $37.4 \%$ & & \\
\hline
\end{tabular}

study settings, sampling methods and respondent characteristics. Respondents in our study were men and women who were members of fitness centers, whereas previous studies in western countries were conducted among male respondents who were not selected from members of fitness centers. ${ }^{19,21}$ Those results of the studies showed that muscle dysmorphia not only suffered by bodybuilder but also general people.

Our results indicate that the muscular/ athletic internalization is the predictor with the greatest adjusted regression coefficient for muscle dysmorphia $(\beta=0.361)$, followed by media pressure $(\beta=0.277)$, body fat percentage $(\beta=-0.262)$ and body dissatisfaction $(\beta=-0.224)$. People with muscle dysmorphia preoccupied with the idea that their body is either too small or not big enough. The majority of them doing exercise, diet or other things to achieve the muscular body. ${ }^{3}$ Muscular/ athletic internalization also showed significant correlation with muscle dysmorphia. The result is consistent with Grieve framework that showed self-internalization indirectly influence muscle dysmorphia. ${ }^{23}$ Muscular/athletic internalization as a predictor of muscle dysmorphia, also reported in studies in California $(\beta=0.26)^{24}$ and the United States $(\mathrm{r}=0.38) .{ }^{9} \mathrm{~A}$ study in America shows that exercise frequency was associated with positive body image, however the association became weaker when motivation for doing exercises was based on appearance purposes only. ${ }^{25}$ Thus, messages promoting exercise need to de-emphasize weight loss and appearance for positive body image. ${ }^{25}$ A study in Australia also reported that health promotion education can give positive improvement for increasing self-esteem, body image and drive for muscularity in males, while improve eating disorder inventory drive for thinness, eating disorder examination and excessive exercise in females. ${ }^{26}$ The results of this Australian study showed that health promotion efforts are able to change community perception of body image and reduce excessive exercises.
Individuals often perceive pressure from the media to achieve impossible body standards, and such media pressure can lead to the development of muscle dysmorphia. ${ }^{23}$ It is proven by multivariate analysis that showed significant result of media pressure and muscle dysmorphia. Correlation of media pressure and muscle dysmorphia also reported to give similar results in a Florida study $(\beta=0.46)^{27}$, whereas the results of a study in the United States (2015) showed a very small correlation $(r=0.02)$ between the effect of the media with muscle dysmorphia. ${ }^{9}$ This may be due to the increasing number of internet users globally. ${ }^{28}$ A further analysis in our study shows that media pressure is correlated with social comparison $(\mathrm{r}=0.260)$, however, it is not directly correlated with body dissatisfaction. The analysis shows that social comparison is correlated with body dissatisfaction $(r=-0.197)$. These results comply with Cafri framework which explains that media pressure is not directly correlated with body dissatisfaction but correlated with social comparison. This means that media pressure can lead someone to compare his/her body with others. ${ }^{29}$ In our study, the media perceived to give highest pressure to respondents was Instagram with the most type of pressure is related to improvement of personal appearance.

Body fat percentage in our study negatively correlated with muscle dysmorphia. It is likely because people who suffer from muscle dysmorphia are mostly people who do bodybuilding/ weightlifting activities. ${ }^{29}$ These activities make their body fat levels lower compared to people with normal physical activity. This study, however, cannot show whether body fat percentage is one of predictors for muscle dysmorphia as shown by Cafri framework ${ }^{29}$, as our study was conducted with a cross sectional design and all respondents were fitness center member. In contrast to the results of our study, studies in the United States ${ }^{30}$ and Turkey ${ }^{16}$ show that body fat percentage is not related to muscle dysmorphia. This is likely due to the fact that the study conducted in the United 
States compared weighlifter with ED and non-ED students, whereas in Turkey the body fat percentage was measured with the perception of body fat using the body builder image grid.

Body dissatisfaction is one of the variables that is directly related to muscle dysmorphia in the Cafri framework. ${ }^{29}$ People with muscle dysmorphia endlessly ruinate on thoughts of their body being too small and develop exercise rituals to placate those feelings. ${ }^{3,31}$ Body dissatisfaction was reported to give similar results in a study in Minnesota USA $(\beta=-0.540){ }^{32}$ In that study it was reported that body dissatisfaction had a negative correlation with muscle dysmorphia score ${ }^{32}$, which means that the lower the value of a person's body satisfaction, the higher the possibility of suffering muscle dysmorphia. These results can explain the definition of individuals with muscle dysmorphia, i.e they are never satisfied with their body shape, especially the size of their muscles. ${ }^{3}$

As have been explained above, body dissatisfaction is correlated with social comparison and social comparison is correlated with media pressure $^{29}$, which means that media pressure can lead people to compare themselves with others and result in body dissatisfaction.

In our study, there was no significant relationship between muscle dysmorphia with age, nutritional status, fat free mass index, thin/low body fat internalization, family pressure, peer pressure and social comparison.

Questionnaire used in this study is translated from the original version in English, thus there are possibly some changes in the meaning of the questions. Our study was carried out only in one city, so the generalization of the results must be taken in caution.

\section{CONCLUSION}

The prevalence of muscle dysmorphia in members of fitness center in Denpasar City is higher than in other countries. Variables that found to have significant correlation with occurrence of the muscle dysmorphia are muscular/athletic internalization, media pressure, body fat percentage and body dissatisfaction. Health education on the importance of positive body image and the influence of social media needs to be enhanced. One of the potential social media channels can be used for providing this education is Instagram as it was mentioned to provide the highest pressure towards improvement of personal appearance. Given the importance of the problem of muscle dysmorphia, further research into this field of study is needed in order to develop prevention programs in this sub-population.

\section{ACKNOWLEDGEMENTS}

We would like to thank the respondents, the managers of the fitness centers in Denpasar, the enumerators, Dr. dr. Anak Agung Sagung Sawitri, $\mathrm{MPH}$ for assisting in the data analysis and Dr. dr. G.N Indraguna Pinatih, M.Sc. Akp, Sp.GK for providing guidance in the preparation of the study instruments.

\section{AUTHOR CONTRIBUTION}

VS designed and conceived the study, collected and analysed the data, wrote the first draft of the manuscript and edited the manuscript. DNW was involved in the design and conception of the study, provided feedback and edited the manuscript. PAG was involved in the design and conception of the study.

\section{CONFLICT OF INTEREST STATEMENT:}

\section{None declared}

\section{REFERENCES}

1. Rehm J, Shield KD. Global burden of disease and the impact of mental and addictive disorders. Curr Psychiatry Rep. 2019;21(2):10.

2. WHO. Depression and other common mental disorder. World Health Organization [Internet]. Geneva; 2017. Available from: https://apps.who.int/iris/bitstream/ handle/10665 /254610/who-msd-mer-2017.2.

3. American Psychiatric Association. Diagnostic and statistical manual of mental disorders: DSM-5. fifth. Washington, DC: Arlington, VA, American Psychiatric Association; 2013 [cited 2019 Feb 18]. Available from: https://www.worldcat.org/title/diagnostic-and-statisticalmanual-of-mental-disorders-dsm-5/oclc/847226928/ viewport.

4. Babusa B, Czeglédi E, Túry F, Mayville SB, Urbán R. Differentiating the levels of risk for muscle dysmorphia among Hungarian male weightlifters: a factor mixture modeling approach. Body Image. 2015;12(1):14-21.

5. Campagna JDA, Bowsher B. Prevalence of body dysmorphic disorder and muscle dysmorphia among entry-level military personnel. Mil Med. 2016;181(5):494.

6. Pope CG, Pope HG, Menard W, Fay C, Olivardia R, Phillips KA. Clinical features of muscle dysmorphia among males with body dysmorphic disorder. Body Image. 2005;2(4):395-400.

7. Phillips KA, Menard W. Suicidality in body dysmorphic disorder. Am J Psy. 2006;163(7):1280-1282.

8. De La Poza E, Jódar L, Alkasadi MSS. Modelling the propagation of adult male muscle dysmorphia in Spain: economic, emotional and social drivers. Appl Econ. 2015;47(12):1159-1169.

9. Diehl BJ, Baghurst T. Biopsychosocial factors in drives for muscularity and muscle dysmorphia among personal trainers. Cogent Psychol. 2016;3:1243194.

10. Nieuwoudt JE, Zhou S, Coutts RA, Booker R. Symptoms of mucle dysmorphia, body dysmorphic disorder, and eating disorders in a nonclinical population of adult male weighlifters in Autralia. J Strength Cond Res. 2015;29(5):1406-1414. 
11. Cella S, Iannaccone M, Cotrufo P. Muscle dysmorphia: a comparison between competitive bodybuilders and fitness practitioners. J Nutr Ther. 2012;1:12-18.

12. Longobardi C, Prino LE, Fabris MA, Settanni M. Muscle dysmorphia and psychopathology: Findings from an Italian sample of male bodybuilders. Psychiatry Res. 2017;256:231-236.

13. Singh Sandhu J, Kishore S, Shenoy S, Singh Randhawa H. Muscle dysmorphia and personality trait: a significant link in bodybuilders. J Postgrad Med Educ Res. 2013;47(2):7782 .

14. Guerra-torres JH, Arango-vélez EF. Muscle dysmorphia among competitive bodybuilders. Rev Politécnica. 2015;2351:38-48.

15. Hitzeroth V, Wessels C, Zungu-Dirwayi N, Oosthuizen P, Stein DJ. Muscle dysmorphia: a South African sample. Psychiatry Clin Neurosci. 2001;55:521-523.

16. Devrim A, Bilgic P, Hongu N. Is there any relationship between body image perception, eating disorders, and muscle dysmorphic disorders in male bodybuilders? Am J Mens Health. 2018;12(5):1746-1758.

17. Dhiana MA, Dieny FF. Hubungan muscle dysmorphia dengan asupan energi dan zat gizi makro pada pria dewasa usia 19-29 tahun anggota Flozor Sport Club Semarang [The relationship of muscle dysmorphia with energy intake and macro nutrition for adult men age 19-29 years members of Flozor Sport Club Semarang]. J Nutr Coll. 2014;3(4):972981.

18. Iswidyanti S, Hamidah. Hubungan antara perfeksionisme dengan kecenderungan muscle dysmorphia pada pria dewasa awal pengguna pusat kebugaran [The relationship between perfectionism and muscle dysmorphia in early adult fitness center users]. Psikology Klin dan Kesehat Ment. 2018;7:61-71.

19. Bo S, Zoccali R, Ponzo V, Soldati L, De Carli L, Benso A, et al. University courses, eating problems and muscle dysmorphia: are there any associations? J Transl Med. 2014;12(1):221.

20. Zeeck A, Welter V, Alatas H, Hildebrandt T, Lahmann C, Hartmann A. Muscle dysmorphic disorder inventory (MDDI): validation of a German version with a focus on gender. PLoS One. 2018;13(11):1-13.

21. Lechner T, Gill E, Drees M, Hamady C, Ludy M-J. Prevalence of disordered eating and muscle dysmorphia in college students by predominant exercise type. Int J Exerc Sci. 2019;12(4):989-1000.

22. Meinich-bache K. Muscle dysmorphia among men with gym membership: an investigation of prevalence and potential corelates. Researchgate. Theses Agder University; 2019 [cited 2019 oct 15]. Available from: https://doi. org/10.13140/rg.2.2.22448.40967.

23. Grieve FG. A conceptual model of factors contributing to the development of muscle dysmorphia. Eat Disord. 2007;15(1):63-80.

24. Klimek P, Murray SB, Brown T, Gonzales M, Blashill AJ. Thinness and muscularity internalization: associations with disordered eating and muscle dysmorphia in men. Int J Eat Disord. 2018;51(4):352-357.

25. Homan KJ, Tylka TL. Appearance-based exercise motivation moderates the relationship between exercise frequency and positive body image. Body Image. 2014;11(2):101-108.

26. Yager Z, Dea JO. A controlled intervention to promote a healthy body image, reduce eating disorder risk and prevent excessive exercise among trainee health education and physical education teachers. Health Educ Res. 2010;25(5):841-52.

27. Cafri G, Van den Berg P, Thompson JK. Pursuit of muscularity in adolescent boys: relations among biopsychosocial variables and clinical outcomes. J Clin Adolesc Psychol. 2006;35(2):285-291.

28. Ministry of Communication and Information. Pengguna internet Indonesia nomor enam dunia [The number of Indonesian internet users is at the sixth position worldwide]. Kominfo. 2018 [cited 2019 oct 15]. Available from: https://kominfo.go.id /index.php/content/detail/4286/ pengguna+internet+indonesia+nomor+enam+dunia/0/ sorotan_media

29. Cafri G, Thompson JK, Ricciardelli L, McCabe M, Smolak L, Yesalis C. Pursuit of the muscular ideal: physical and psychological consequences and putative risk factors. Clin Psychol Rev. 2005;25(2):215-239.

30. Robert O, Harrison P, James H. Muscle dysmorphia in male weightlifters: A case-control study. Am J Psychiatry. 2000;157(8):1291-1296.

31. Morgan J. The invisible man. New York: Routledge; 2008. Available from: http://imdb.com/title/tt0032635

32. Jones SA. Factors related to muscle dysmorphia symptomology in adolescent males. ProQuest Dissertations and Theses. Walden; 2017 [cited 2019 oct 15]. Available from: http://elib .tcd.ie/login?url=https://search.proquest. com/docview/1870038129

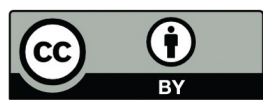

This work is licensed under a Creative Commons Attribution 